\title{
Mídia e Produção de Modos de Existência'
}

\author{
Cecília Maria Bouças Coimbra ${ }^{2}$ \\ Universidade Federal Fluminense
}

\begin{abstract}
RESUMO - Pretende-se levantar como os meios de comunicação de massa são também responsáveis pela produção de modos hegemônicos de ser e de existir no mundo. Apresenta-se um rápido histórico do crescimento e expansão da mídia no Brasil e de sua centralização e controle. A seguir, através de como vêm funcionando os mass-media, apontam-se como vão sendo forjadas essas normas hegemônicas de se estar no mundo. Finaliza-se assinalando-se que, apesar desse poderio, há estratégias de resistência construindo, mesmo que local e provisoriamente, outros modos de vida, outros modos de existência.
\end{abstract}

Palavras-Chave: Mass-media; modos de existência; sociedade do espetáculo.

\section{Media and Production of Ways of Existence}

\begin{abstract}
The intention here is to find out how the mass-media elements are also responsible for the production of hegemonic patterns, and their influence for the behavior and existence in the world. It is presented a short description of the expansion and development of the media in Brazil, approaching its centralization and control. In the following point, based on the way how the mass-media have worked, it is viewed the process by which these hegemonic forms of "taking part of the world" are created. On the one hand it is clear the power of media, on the other hand it is relevant the growth of alternative strategies for resistance that, even temporary and acting in local area, have created new ways of life and forms of existence.
\end{abstract}

Key-words: Mass-media; ways of existence; spectacle society.

Este artigo é parte de uma pesquisa que levantou como estão sendo produzidos, cotidianamente, alguns aspectos da chamada "violência urbana" sobre "as mentes e os corações" de alguns segmentos de nossa população nas grandes cidades brasileiras através da análise de um acontecimento ocorrido no Rio de Janeiro: "Operação Rio"3.

Nesta pesquisa apontamos algumas formas de pensar e agir presentes nos centros urbanos como os aplausos e apoios aos grupos de extermínios e chacinas, aos linchamentos, à pena de morte e às mais diferentes violações de direitos humanos como construções competentes e eficazes advindas também dos meios de comunicação de massa. Através de diferentes falas apresentadas em notícias, manchetes, editoriais e cartas de leitores em quatro jornais do eixo Rio - São Paulo (O Globo, Jornal do Brasil, Folha de São Paulo e $O$ Estado de São Paulo) no período de janeiro de 1994 a maio de $1995^{4}$, levantou-se alguns aspectos sobre a violência urbana no Brasil através de como foi sendo preparada e apresentada a "Operação Rio".

1 Este trabalho é uma pequena parte da pesquisa de Pós-Doutorado da autora, "Discursos sobre Segurança Pública e Produção de Subjetividades: a violência urbana e alguns de seus efeitos", realizada no Núcleo de Estudos de Violência da USP, em 1998.

2 Endereço: Rua Maranhão, 206, Méier - Rio de Janeiro-RJ. CEP: 20720-230.E-mail: gtnm@alternex.com.br

3 A "Operação Rio" foi a ocupação das áreas fluminenses consideradas perigosas - principalmente favelas - pelas Forças Armadas, policiais militares e civis do Rio de Janeiro, com a justificativa de acabar com a violência e o narcotráfico no estado. Abarcou o período de novembro de 1994 a maio de 1995 .

4 Época que corresponde ao aparecimento na grande imprensa de notícias que apontavam para a "Operação Rio".
Os quatro jornais pesquisados fazem parte de um tipo de imprensa escrita e dirigida, em especial, às classes médias urbanas. Tratou-se, portanto, de um recorte propositalmente pensado.

Esta imprensa pesquisada trouxe de forma privilegiada algumas falas que foram colocadas em análise. Os jornais constituem-se em uma fonte rica, pois veiculam um maior e mais extenso número de informações sobre as notícias divulgadas. Entretanto, não foram ignoradas as produções forjadas pelos demais meios de comunicação de massa: elas estiveram presentes, atravessando, influenciando as análises realizadas. Sabemos que as notícias veiculadas por qualquer órgão de informação não são isoladas, elas são desdobramentos $e$ complementação de outras que apareceram na TV, no jornalismo elou na imprensa escrita. (Coimbra, 1998, p. 3).

Além da pesquisa nos quatro jornais escolhidos, algumas fontes documentais foram analisadas como boletins e relatórios sobre a questão da violência urbana em geral no Brasil e, em especial, sobre a "Operação Rio".

Ao cotejar todos esses dados e informações obtidos com as pesquisas nos jornais, nas fontes documentais e nas entrevistas realizadas não estivemos à procura de uma "verdade", de "fatos objetivos" sobre o acontecimento "Operação Rio" e seus efeitos. Nossa abordagem nos faz entender a "verdade", não como absoluta, objetiva e/ou neutra, mas como uma instituição ${ }^{5}$ produzida de formas diferentes, se-

5 Por instituição, dentro do referencial socioanalítico francês, entendemos não o estabelecimento ou local geográfico, mas relações e cam- 
gundo os diferentes atravessamentos históricos. Sabemos que os editoriais, as cartas de leitores, as falas das autoridades também não são neutros, pois estão, como tudo no mundo, contaminados, atravessados por diferentes forças, diferentes movimentos.

Essa concepção de pesquisa, entendendo-a também como uma instituição, aponta para o pesquisador implicado, aquele que recusa sua neutralidade, procurando sempre, dessa forma, derrubar as barreiras entre sujeito que conhece e objeto a ser conhecido. Essa forma de se entender a pesquisa afirma, ainda, "que pesquisador e pesquisado, sujeito e objeto do conhecimento se constituem no mesmo momento, no mesmo processo." (Coimbra, 1998, p. 5).

Refere-se assim, o primeiro capítulo desta pesquisa, aos meios de comunicação de massa, em especial à mídia impressa. Não pretendemos fazer um estudo aprofundado sobre este equipamento social, apenas apontar algumas de suas produções e alguns efeitos daí advindos que nos interessaram mais diretamente para a pesquisa realizada.

Este artigo, portanto, pretende apontar, de forma bem geral, algumas produções mediáticas e alguns de seus efeitos para que possamos entender um pouco como alguns modos de existência dominantes hoje estão sendo forjados e disseminados em nosso cotidiano

Partimos do pressuposto de que a mídia é atualmente um dos mais importantes equipamentos sociais no sentido de produzir esquemas dominantes de significação e interpretação do mundo e que os meios de comunicação, portanto, "falam pelos e para os indivíduos" (Guattari \& Rolnik, 1985, p.58). Este equipamento não nos indica somente o que pensar, o que sentir, como agir, mas principalmente nos orienta sobre o que pensar, sobre o que sentir. Assim, a mídia nos coloca certos temas e nos faz crer que estes é que são os problemas importantes sobre os quais devemos pensar e nos posicionar. Através da ininterrupta construção de modelos de unidade, de racionalidade, de legitimidade, de justiça, de beleza, de cientificidade os meios de comunicação de massa produzem formas de existir que nos indicam como nos relacionar; enfim, como ser e viver dentro de um permanente processo de modelização.

\section{Crescimento e Monopólio}

Nos anos 60, verificou-se um notável desenvolvimento dos meios de comunicação de massa no Brasil, em especial, após o golpe militar de 1964. Principalmente, as telecomunicações - exigência clara nos planos para se aperfeiçoar e expandir a "defesa nacional" - permitiu que, do Oiapoque ao Chuí, programas pudessem ser vistos e ouvidos pelos mais diferentes segmentos de nossa população. Sob os slogans do desenvolvimento, da modernização aliados à segurança na-

pos de forças instituídos, produzidos e percebidos como naturais que se opõem constantemente a outros campos de forças instituintes. Daí, dizemos que as instituições, diferentemente como são vistas, não são estáticas, cristalizadas e, portanto, eternas. Estão em constante movimento, em devir permanente. cional, os meios de comunicação tornaram-se prioridade para o regime militar.

Esta "modernização conservadora", no dizer de Muniz Sodré (1992), desenvolveu a tecnoburocracia, que "combinou tecnologia com interesses militares e comerciais" (p. 32), tendo características transnacionais.

O crescimento e a expansão dos meios de comunicação significou, paradoxalmente, sua centralização e controle por uns poucos - tendência ocorrida mundialmente a partir da segunda metade do século XX. É, ainda, Muniz Sodré (1992) que afirma serem hoje a imprensa escrita e a radiodifusão setores extremamente "familiais", pois "(...) nove clãs controlam mais de $90 \%$ de toda a comunicação social brasileira. Trata-se de jornais, revistas, rádios, redes de televisão, com mais de $90 \%$ de circulação, audiência e produção de informações (...) controlados pelo estamento dominante" (p.43).

Este monopólio dos meios de comunicação - após anos de ditadura militar e de concessões escandalosas e praticamente ilegais - particularmente em certas regiões do Brasil, tem sido preocupante, pois "não se adquire apenas um palanque mediático, mas quase um fórum de decisões políticas" (Gomes, 1994, p. 63), visto que se intervém abertamente em questões as mais diversas, orientando-as - com a "aprovação" da opinião pública - para os caminhos e desfechos que interessam ao que é dominante.

Em pesquisa realizada na Biblioteca Nacional sobre os jornais em circulação no Rio de Janeiro, desde 1930, Silva e Lima (1997) encontraram os seguintes números, bastante significativos, que nos apontam claramente para o gradativo monopólio da imprensa escrita no Brasil a partir dos anos 60. Na década de 30, tínhamos 41 jornais; na de 40, eram 43 jornais; na de 50 , o número aumentou para 52 jornais. A partir dos anos 60 começaram a cair assustadoramente, quando passamos a ter 22 jornais. Na década de 70 , continuou a redução e ficou-se com 16 jornais e na de 90 , temos 07 jornais ${ }^{6}$.

Este contexto não se diferencia de outros países capitalistas, sejam latino-americanos ou europeus, onde o monopólio dos meios de comunicação é hoje uma realidade incontestável.

Levantamento realizado por Chomsky (1997) e apresentado na Folha de São Paulo (pp. 8-9) aponta a Rede Globo como fazendo parte dos sete maiores grupos que constituem o chamado "império da mídia", dominando este setor mundialmente. Ao lado da alemã Bertelsmann, da mexicana Televisa, da australiana News Corporation e das norte-americanas Viacom, ABC Disney e Time Warner, a Rede Globo tinha, em 1997 - oficialmente - sob sua tutela um jornal, cinco revistas, uma rádio com 20 emissoras, um canal de TV transmitido por 86 emissoras nacionais, quatro canais internacionais para a Inglaterra, Estados Unidos, Portugal e Brasil, uma empresa de vídeo, uma editora, uma gráfica e três gravadoras de discos.

6 Em 1830, por exemplo, no Rio de Janeiro, tinha-se 53 periódicos circulando (Cardoso \& Araújo, 1992). 


\section{Produzindo Certos Modos de Existência}

Este monopólio das comunicações, esta concentração das informações - característicos do nosso mundo globalizado produzem certos modos de existir e de viver condizentes com a chamada "sociedade de controle"7. Enfatizam-se os valores e as virtudes da instantaneidade, da descartabilidade, da diversificação, do planejamento e ganhos a curto prazo, da capacidade de se movimentar com rapidez.

Segundo Harvey (1993) numa "sociedade do descarte" joga-se fora tudo: valores, estilos de vida, relacionamentos estáveis, apego às coisas, pois tudo torna-se obsoleto. Adquirir uma imagem "competente", "confiável", "pós-moderna" através da compra de um sistema de signos, como roupas de grife, carro da moda, discursos e saberes "avançados" é o significado da vida ${ }^{8}$.

Portanto, além de produzir certos modos de existência e de vida, de estar nas mãos de uns poucos, a mídia funciona organizando diversos e diferentes fluxos de acontecimentos; pela via do espetáculo, das formas dramáticas e sensacionalistas produz identidades, simpatias, prós e contras. À medida, portanto, que organiza os múltiplos fluxos de acontecimentos, a mídia hierarquiza os temas, selecionando os que deverão ser do conhecimento público e, daí, os que deverão necessariamente ser discutidos, debatidos, pensados.

Assim, a lógica mediática é a da homogeneização, do espetáculo, obedecendo ao valor da excepcionalidade, do ser extraordinário, da dramaticidade, da encenação voltada também para a produção de emoções.

A homogeneização presente no funcionamento desta lógica mediática faz com que a linguagem usada seja a "factográfica", onde se trabalha com dicotomias, com binarismos, unicamente com dois valores: o bom e o mau. Na medida em que isto predomina fica-se privado do "discurso matizado e argumentativo" (Loparic, 1995, pp. 1-3). Ou seja, empobrecem-se os acontecimentos, onde a multiplicidade, as diferenças estão ausentes, impondo-se/produzindo-se formas de pensar, sentir e perceber maniqueístas, dicotômicas.

Assim, pela produção e circulação de signos, imagens, subjetividades, "pelo recalcamento e negação de certas realidades", pela sugestão e, portanto, pela criação de um real, de realidades - que passam a ser as que existem objetivamente - os meios de comunicação de massa "simula(m) padrões consensuais de conduta" (Sodré, 1992, p. 45), produzem poderosas e eficientes formas de ser e de estar no mundo; forjam existências, vidas, bandidos, mocinhos, heróis e vilões.

\section{Concluindo}

Fechando este artigo que aborda, em linhas bem gerais, alguns funcionamentos, produções e efeitos dos mass-me-

7 Termo cunhado por Deleuze (1992).

8 Sobre o assunto consultar: Harvey (1993) e Deleuze (1992). dia, outras discussões se fazem pertinentes. Não pretendemos afirmar que, maquiavélica e simplificadamente, somente os meios de comunicação de massa produzem/reproduzem/ fortalecem os modos de existência hegemônicos em nosso cotidiano. Embora em parte construam a realidade, os corpos e os espíritos; embora instalem uma "ditadura suave, persuasiva, subliminar, sem revolta possível, sem prisão, sem guardas, pois as telas substituíram as grades" (Toscani, 1996, p. 170) - já que estamos vivendo num misto de "sociedade de controle" e sociedade disciplinar - há outros equipamentos sociais responsáveis por isto.

Entretanto, apesar deste poderio, por toda parte observamos estratégias e mecanismos presentes em diferentes grupos e movimentos que conseguem, algumas vezes, mesmo que provisoriamente, reverter tais produções hoje hegemônicas. Tais processos de singularização, tais questionamentos aos modos de ser instituídos, são respostas que se nos apresentam e que apontam para a possibilidade de forjar outras percepções, outras formas de se relacionar, outros modos de vida e de existência no plano micropolítico. Nos apontam para uma nova arte de viver, uma "estética da existência", uma outra e diferente "arte de viver contra toda forma já existente ou iminente de fascismo" (Schmid, 1998, p. 105). Ou seja, a "estética da existência" em Foucault nos assinala a possibilidade que temos, nos chama a atenção para “(...) a forma que damos aos objetos da existência e talvez à própria existência. Não é decisivo continuar negando a forma, mas descobrir múltiplas formas com o fito de escapar de uma dominante." (p. 107).

Estas brechas, estes movimentos, muitas vezes, invisíveis, microscópicos, mas que, silenciosamente, subterraneamente, estão produzindo outras realidades e verdades, outras histórias e memórias, são possíveis. Tentar produzi-los, afirmá-los, fortalecê-los, aliarmo-nos à eles tem sido o nosso grande desafio.

\section{Referências}

Cardoso, C.F. \& Araújo, P.H. (1992). Rio de Janeiro. Madrid: Ed. Mapfre Ltda.

Chomsky, N. (1997, 09 de março). O império da mídia. Folha de São Paulo, pp. 8 e 9.

Coimbra, C.M.B. (1998). Discursos sobre segurança pública e produção de subjetividades: a violência urbana e alguns de seus efeitos. Trabalho de Pós-Doutorado, Universidade de São Paulo, São Paulo.

Deleuze, G. (1992). Conversações. (P.P. Pelbort, Trad.). Rio de Janeiro: Editora 34. (Trabalho original publicado em 1990).

Guattari, F. \& Rolnik, S. (1985). Micropolítica: cartografias do desejo. Petrópolis: Vozes.

Gomes, W.S. (1994). Propaganda política, ética e democracia. Em H. Matos (Org.), Mídia, eleições e democracia (pp. 53-90). São Paulo: Scritta.

Harvey, D. (1993). A Condição Pós-Moderna. (A.U. Sobral \& M.S. Gonçalves, Trads.). São Paulo: Loyolla. (Trabalho original publicado em 1989). 
Loparic, Z. (1995, 18 de julho). Sobre a cultura midiática. Folha de São Paulo, pp. 1-3.

Schmid, W. (1998). Reflexões para uma ética segundo Foucault: Estética da Existência. Psicologia: Teoria e Pesquisa, 14 (2), 103-110.

Silva, M.R. \& Lima, S. C. (1997). Tarja nos olhos: uma análise do chamado menor infrator. (Relatório $\mathrm{n}^{\circ} 01$ ). Rio de Janeiro: Universidade Federal Fluminense.
Sodré, M. (1992). O social irradiado! Violência urbana, neogrotesco e mídia. São Paulo: Cortez.

Toscani, O. (1996). A publicidade é um cadáver que nos sorri. (L.C. de M. Guerra, Trad.). Rio de Janeiro: Ediouro. (Trabalho original publicado em 1995).

Recebido em 11.12.2000

Primeira decisão editorial em 27.04.2001

Versão final em 12.06.2001

Aceito em 18.06.2001

\section{MUDANÇA DE ENDEREÇO}

Se você está mudando de endereço por favor notifique $P$ sicologia: Teoria e Pesquisa. Ocasionalmente, assinantes e autores comunicam tardiamente mudança de endereço determinando dificuldades na entrega de nossa revista ou de outras correspondências. Informe imediatamente, se possível com antecedência, qualquer mudança de domicílio para:

Universidade de Brasília - Instituto de Psicologia

Revista Psicologia: Teoria e Pesquisa

Secretaria de Divulgação

70910-900 Brasília DF

Mudanças de endereço poderão também ser comunicadas através do correio eletrônico revptp@unb.br ou do telefone e fax (061) 274-6455. 